\title{
Vorstellung der Autorinnen und Autoren
}

\author{
Clementina Caputo \\ ist Post-Doctoral Researcher im SFB 933 „Materiale Textkulturen“ (Teilprojekt A09) an der Ruprecht- \\ Karls-Universität Heidelberg. Sie ist Teammitglied der Ausgrabungen in Dime seit 2006 sowie in \\ Amheida seit 2009. Sie forscht zu Textträgern aus Keramik aus dem antiken Mittelmeerraum.
}

\section{Paolo Cecconi}

leitet das Stadtarchiv Chemnitz. Zu seinen Forschungsinteressen gehören die frühe christliche Literatur, die Kirchengeschichte, die Sächsische Geschichte und die Historischen Hilfswissenschaften. Zu seinen Veröffentlichungen zählt die Neuedition der lateinischen Übersetzung des Hirten von Hermas.

\section{Laure Chappuis Sandoz}

ist Assoziierte Professorin für Lateinische Sprache und Literatur an der Universität Neuchâtel. Sie ist spezialisiert auf klassische und spätere lateinische Dichtung und interessiert sich insbesondere für Gattungsfragen, Gender Studies sowie für erotische Literatur.

\section{Ulrich Eigler}

ist seit 2005 Ordinarius für Klassische Philologie (Latinistik) an der Universität Zürich. Er arbeitet zur Literatur der augusteischen Epoche, der frühen Kaiserzeit und der Spätantike sowie zum Neulatein. Weitere Schwerpunkte seiner Forschung sind: Antikenrezeption insbesondere in der modernen Literatur und im Film, die Überlieferung der antiken Literatur und ihre medialen Bedingungen, Forschungen zur antiken Sklaverei und ihrer Rezeption.

\section{Adrian Gramps}

wurde am Trinity College Dublin im April 2018 promoviert. Seine Arbeit erforscht die fiktionalen Welten der hellenistischen und römischen Dichtung.

\section{Sam A. Hayes}

promovierte an der University of Exeter in 2016 zu den Lesestrategien, welche in Martials Epigrammen angelegt sind. Er ist Honorary Research Fellow an der University of Exeter und unterrichtet Griechisch und Latein in London.

\section{Gregory 0. Hutchinson}

ist Regius Professor für Griechisch an der Universität Oxford. Er hat neun Monographien geschrieben, die neuste (2018) davon heißt „Plutarch’s Rhythmic Prose“.

\section{Helmut Krasser}

ist seit 1999 Professor für Klassische Philologie (Latinistik) an der Justus-Liebig-Universität Gießen. Seine Forschungsschwerpunkte sind die Literatur der augusteischen Zeit und der Kaiserzeit mit besonderer Berücksichtigung der Interaktion literarischer Texte mit kulturellen und gesellschaftlichen Praktiken (Amphitheater, Triumph, Lesekultur). 


\section{Cecilia Nobili}

ist Research Fellow an der Università degli Studi di Milano. Ihre Forschungsinteressen gelten hauptsächlich der archaischen griechischen Dichtung sowie den Beziehungen zwischen materieller Kultur und griechischer Literatur. Ihre aktuelle Buchpublikation trägt den Titel „Corone di gloria. Epigrammi agonistici ed epinici dal VII al IV secolo a. C.“ (Alessandria 2016).

\section{Tom Phillips}

ist Supernumerary Fellow in Classics am Merton College Oxford und der Autor der Monographie „Pindar's Library: Performance Poetry and Material Texts“ (Oxford 2016). Seine aktuelle Forschung fokussiert auf lyrische Dichtung, hellenistische Poesie sowie die antike Wissenskultur.

\section{Anna Plisecka}

ist Post-Doctoral Researcher an der Rechtswissenschaftlichen Fakultät der Universität Zürich. Ihr Forschungsschwerpunkt liegt auf dem Römischen Recht und der Rechtspraxis in den römischen Provinzen. Derzeit bereitet sie eine Monographie über die apokrimata des Septimius Severus und Caracalla vor.

\section{Cornelia Ritter-Schmalz}

ist Wissenschaftliche Assistentin am Lehrstuhl für Klassische Philologie (Latinistik) der Universität Zürich. Sie arbeitet über mediale Selbstreflexion in augusteischen Gedichtbüchern, insbesondere bei Properz. Weitere Interessensgebiete sind die antike Sklaverei sowie die Antikenrezeption in der gegenwärtigen Populärkultur.

\section{Cédric Scheidegger Lämmle}

ist Oberassistent am Fachbereich Latinistik der Universität Basel und Affiliated Lecturer an der Faculty of Classics der Universität Cambridge. Nach einem ersten Buch zur Idee des literarischen Euvres in der lateinischen Dichtung (,Werkpolitik in der Antike“, München 2016) gilt seine Forschung derzeit vor allem Ciceros Reden, der spätantiken Dichtung und der Antikenrezeption.

\section{Jochen Schultheiß}

habilitierte sich in Würzburg mit einer Monographie zu den Entscheidungsszenen im römischen Epos. Zur Zeit arbeitet er im Rahmen eines Projektes zu dem Humanisten Joachim Camerarius d. Ä. und widmet sich dort insbesondere den griechischen Werken. Seine Forschungsinteressen liegen in den Bereichen der christlichen Spätantike, des römischen Epos und der neulateinischen Literatur.

\section{Raphael Schwitter}

ist Post-Doctoral Researcher an der Katholischen Universität Eichstätt-Ingolstadt. Zu seinen Forschungsgebieten zählen neben der Epistolographie, der lateinischen Kleinpoesie und der Rezeption antiker Literatur auch die medialen Ausdrucksformen der römischen Geschichts- und Memorialkultur.

\section{Hartmut Wulfram}

ist Professor für Neulateinische Philologie und Klassische Latinistik an der Universität Wien. Einer seiner Forschungsschwerpunkte befasst sich mit Literatur und (Inter-)Medialität, d. h. ästhetischen Strategien und Implikationen in Zusammenhang mit dem sich historisch wandelnden Literaturmedium „Buch“, wie „Paratext“ oder „Makrotext“ - nicht selten im Wechselspiel mit ursprünglich lebensweltlichen Textsorten wie Brief und Epigramm oder außerliterarischen Kunstformen wie Architektur und Druckgraphik. 